COMUNICACIÓN Y MEDIOS n. 24 (2011). ISSN 0719-1529. pp. 188-200.

Instituto de la Comunicación e Imagen. Universidad de Chile

\title{
La Memoria filmada
}

\section{Filmed Memory}

\author{
Dino Pancani Corvalán \\ Universidad Alberto Hurtado \\ dpancani@uahurtado.cl
}

\begin{abstract}
Resumen Las películas que tratan el pasado reciente chileno y argentino, plantean interrogantes que conllevan hipótesis de trabajo desde dentro del film y su relación con el afuera. Contenido que se explica desde el entorno de la película: ¿Existe concordancia entre los argumentos históricos y sociológicos que explican la caída de las dictaduras militares y el tránsito a la democracia, con el contenido de las historias narradas audiovisualmente?, ¿la propuesta de construcción de memoria colectiva es incluyente?, ¿hasta dónde la producción cultural cinematográfica es reflejo de los procesos políticos dominantes? Estas preguntas traen implícita una hipótesis: Las películas podrían estar asociadas a discursos dominantes que invisibilizan y/o condenan formas de resistencia.
\end{abstract}

Palabras clave Dictadura, transición, cine, representación, memoria.

\begin{abstract}
The films about the recent past of Chile and Argentina bring questions that lead to the work hypothesis from inside the film and its relationship with the outside. Content that is explained from the context of the film: Is there agreement between the historic and sociologic theme that explained the fall of the military dictatorships and their transition to democracy, with the content of the audio visually told stories? Is the proposed construction of collective memory inclusive? Up to what point is the cinematographic cultural production a reflection of the dominant political processes? It is implicit within these questions a hypothesis: the films could be related to the dominant discourses that turn invisible and/or condemn the various forms of resistance.
\end{abstract}

Key words Dictatorship, transition, film, representation, memory. 


\section{La memoria filmada}

Los procesos de memoria que se presentan a través de la cinematografía producida sobre la historia reciente de Chile y Argentina, invitan a reflexionar el periodo desde el presente, asumiendo las múltiples lecturas que tiene un pasado convulso.

Este ejercicio intelectual surge cuando, al estar frente a una película, que relata un tipo de memoria, el espectador se cuestiona y trata de fijar ¿qué proceso o acontecimiento está relatando el personaje? ¿a quién le dirige el relato y por qué se decide a narrar? ¿qué contenido de memoria aparece implícita o explícitamente dentro de la película y cuál es el diálogo que provoca con el afuera? ¿qué función cumple la memoria puesta en circulación? Estas interrogantes ponen de manifiesto, además, una serie de decisiones que enfrenta el realizador al comenzar el proceso creativo, las cuales determinan no sólo el artefacto y el formato a emplear, por ejemplo, por qué usar el formato audiovisual, también lleva a un proceso cognitivo que requiere de un saber o, al menos intuir, cuáles serán los caminos para alcanzar el objetivo planteado.

A ello, se le debe sumar, que las narraciones buscan espacios que les permitan decir lo no dicho, o no explicitado en obras anteriores, pretenden tener una cuota de novedad en lo que se dice y el cómo se dice, "qué contar y cómo transmitir asoman por lo tanto como dos aspectos de una misma cuestión, porque la idea de que necesitamos revisar las experiencias de nuestro pasado reciente insiste; y de esa insistencia surge la pregunta acerca de cómo hacer para atravesar las versiones instituidas y producir nuevas interpretaciones” (Oberti, Pittaluga, 2006, p.19). Desafío asumido por la mayoría de los creadores e investigadores que intentan aportar, desde distintos puntos de vista, al proceso de reconstrucción de memorias, siempre insatisfechas.

La temática que se vincula directamente con el desarrollo de los procesos de memoria en Chile y Argentina, tuvo características propias en cada país. Por una parte, en "Chile, la historia política del pasado reciente se ha ido moviendo desde el análisis estructural de las transformaciones socio políticas, en perspectiva de mediano plazo, a la recuperación de la experiencia subjetiva de la política” (Moyano, 2010, p.191), lo cual mantuvo a memorias individuales fuera de los circuitos masivos, y por ende, ausente de las disputas de la memoria. Por otra, en Argentina, debido a la masividad de la represión, se buscó instalar una memoria que diera cuenta de una realidad individual con ribetes colectivos, se trataba de ponerle rostros a los obscenos números de detenidos desaparecidos y ejecutados políticos, de descubrir la historia de los nombres de las víctimas de los militares, de establecer una verdad que permitiera iniciar el camino de la justicia. 
Un elemento común entre ambos países, es que la conducción transicional se construyó teniendo en consideración el ejercicio del poder que mantuvieron los militares durante el primer periodo de las transiciones, que se manifestó a través de movimientos de tropas que pusieron en tensión el incipiente sistema democrático. En Argentina, en 1987 comandado por el teniente coronel Aldo Rico y en 1990, encabezado por el coronel Mohamed Ali Seineldín. Mientras que en Chile hubo dos episodios similares, en 1990 y 1993, ambos dirigidos por el comandante en jefe del ejército, Augusto Pinochet Ugarte.

Este contexto político y sociocultural, motivo que las narraciones presentaran a la verdad como un concepto anterior a un anhelo que marcaría las siguientes décadas: la justicia. Se trataba de visibilizar ante la opinión pública que se habían violado los derechos humanos de miles de personas y que aquello requería de un reconocimiento del Estado, el cual debía estar cruzado por el involucramiento del poder judicial. En Argentina esta estrategia puso en relieve la "fragilidad del criterio de justicia invocado para recuperar a las víctimas como inocentes y, por lo tanto, pertenecientes a un campo democrático ajeno al ejercicio de la violencia política denotada, por un lado, la inseguridad con que esta sociedad se movía en el terreno poco explorado de los derechos y garantías individuales y el constitucionalismo liberal" (Novaro, Parlemo, 2003, p. 488). El caso chileno, tuvo expresiones similares, las cuales se materializaron a través de diversas expresiones; el lenguaje, las narraciones del periodo, la valoración de la lucha desarrollada por colectivos e individuos que no tuvieron cabida en el modelo transicional propuesto, "la transición chilena oficializó un discurso de la memoria que, a través del consenso y la reconciliación, privilegió narrativas suturadoras y apaciguadoras para que las voces incomodantes de la queja, la confrontación y la impugnación, no desajustaran la prudente búsqueda de equilibrios entre pasado y presente que controló la política institucional." (Richard, 2010, p.19) Esa posición, en aquellos años, enaltecía la figura del combatiente antidictatorial en el marco de la denominada no violencia activa.

En ese marco, la cinematografía en Chile y Argentina, intentó tímidamente escapar de la judicialización de las historias y proponer una memoria que diera cuenta de una verdad cotidiana, mínima por su alcance, pero contundente en sus argumentos. Promovió el recuerdo parcial de protagonistas sin origen político ni responsabilidades, sin presente ni futuro, sin que los conceptos de justicia aparecieran mencionados en las obras, concepto que no se evoca ni se desecha. Se muestran condiciones de abuso en donde los protagonistas de las películas son perseguidos sin que los motivos queden en evidencia, ni su posible militancia política, se exhiben actores como víctimas/inocentes de las brutalidades de la dictadura, con un pasado que se circunscribe a acontecimientos referenciales, sin 
voz ni imagen. En argentina, incluso se enaltecen obras, como La Historia Oficial (Argentina, 1985) que sirven "para explicar o incluso justificar el silencio de la mayoría bajo la excusa de que no sabían. Y también los expió, permitiéndoles alcanzar la redención a través del conocimiento y el sufrimiento. Ya que la administración de culpa con respecto a lo sucedido es un tópico sumamente espinoso, se entiende que los espectadores argentinos apreciaran una película que los tranquilizó al asegurarles que no había sido su culpa” (Bratkievich, 2010, p.367)

Durante este primer periodo, se optó por crear o enfatizar en personajes difusos, inocentes o vinculados precariamente a la resistencia a las dictaduras, por ejemplo; el relegado de La Frontera (Chile, 1991). Se vuelve invisible a los sujetos que orgánicamente decidieron enfrentar a los militares. Alternativa que difiere de la literatura testimonial, de archivos de organismos vinculados a la defensa de los derechos humanos y de los informes de la Comisión de la Verdad y la Reconciliación, en el caso de Chile, y del escrito final de la Comisión Nacional sobre la Desaparición de Personas, en Argentina. En Chile, a "diferencia de lo ocurrido con el "Nunca Más!" argentino, la neutra sequedad de los Informes de la memoria chilena sobre la tortura evitó la vibración testimonial de las experiencias límite, para que los chocantes desbordes de estos relatos arrancados de zonas de subjetividad fuera de control no atentaran contra el acuerdo básico de entendimiento y consentimiento en torno a los males del pasado, que exigía, mesuradamente, la reconciliación.” (Richard, 2010, p.38).

En el cine, este periodo de transición democrática tuvo de parte de los organismos de derechos humanos la voluntad de crear narraciones ausentes de toda expresión de violencia por parte de las víctimas, estrategia que construyó transversalmente un relato "eficaz en la estrategia de ampliar la base de legitimidad del movimiento, logrando mayor reconocimiento social y receptividad de sus demandas" (Amado, 2009, p.15).

Esta característica logró otorgar verosimilitud a los organismos de derechos humanos, pero no permitió su inclusión a la naciente administración de las transiciones democráticas. Los nuevos gobiernos civiles, al asumir que "la memoria tiene entonces un papel altamente significativo como mecanismo cultural para fortalecer el sentido de pertenencia a grupos o comunidades" (Jelin, 2002, p.10), impiden la cohesión y valoración de sectores que luchando en contra de las dictaduras no se veían representados por los nuevos gobiernos. Dentro de esa estrategia el cine puede definirse como un vehículo de memorias que podría incitar, motivar o consolidar grupos adversos al proyecto negociador que marcó los primeros años de democracia, cuyos líderes se sentían como LA alternativa posible y LA única heredera de la lucha en contra de las dictaduras, por ello, no se estimula ni se amplían las voces que pueden dar cuenta de otras memorias, sino que se invierta 
precariamente en obras que presentan una interpretación coincidente o no cuestionadora de la memoria dominante.

En un primer momento, el relato del director de cine surge principalmente desde los detalles, a partir de episodios que le permiten contar una historia más amplia, novedosa o que acredita por vías informales, ajenas al Estado, acontecimientos con dimensiones individuales y colectivas. Se cuentan historias, en donde la/los protagonistas sufren el abandono institucional, la sospecha de sus compañeros, la tensión entre el olvido y el recuerdo, la resistencia de la memoria, la privacidad del dolor ante un abuso público. Condiciones que tienen una dimensión individual y otra pública, como se aprecia en Un Muro de Silencio, (Argentina, 1993).

La privacidad, la intimidad hace contacto con la experiencia de miles de otras/os que padecieron el horror de la pérdida producto de la acción de agentes del Estado. Son cintas que se niegan "a crear una versión única de los sucesos narrados, no identificada como una mera transcripción del mundo real. Son films que explicitan, con distintos grados de intensidad, que son el producto de la mirada y el accionar de sus creadores" (Sartora y Rival, 2007, p.95), obras que comprometen decisiones éticas, que determinan qué y por qué contar; estéticas, en el sentido del cómo contar; contextuales, referido a qué acontecimientos y representaciones icónicas se fijaran, y sociopolíticas, vinculadas a qué se explicita y qué se evoca a la memoria del espectador.

Se relatan hechos en donde la certificación jurídica pasa a ser un elemento prescindible, y ello, no atenta en contra de la credibilidad de la cinta, se puede contar un acontecimiento sin necesidad de que éste sea parte de las memorias oficiales o que goce del reconocimiento institucional, son historias que, al reconocerse en otras, provocan fiabilidad, aunque no sean valoradas. Existen historias que se presentan como reconocimientos a militantes destacados, "Las jerarquías se trasladan a los muertos, como puede verse en diversos ejemplos de la memoria guerrillera: en el límite sólo las muertes heroicas, en combate, merecen ser celebradas. Las conmemoraciones militantes que en los últimos años han buscado resaltar la figura del combatiente en desmedro de la simple víctima," (Vezzeti, 2009, p.195). Como parte de este tipo de filmografía, vinculada más a los movimientos y/o partidos que a los procesos políticos de aquel periodo, destacan obras que enarbolan la figura de ex guerrilleros/as, que reiteran, junto al director, su convicción y accionar en el marco de la dictadura y la transición democrática. También, se construyen como una plegaria a un héroe de la resistencia a la dictadura, mitos que son capaces de poner las condiciones de su cautiverio y de su seguro asesinato. Una construcción épica de personajes vinculados a la dirigencia 
del grupo guerrillero. Se puede apreciar en Calle Santa Fe, (Chile, 2007) y Gaby la Montonera, (Argentina 2008), entre otras películas.

Los realizadores hablan a través de personajes de ficción, de testimonios convertidos en personajes, y ese mensaje siempre tiene un marco de memoria que permite que sea reconocible por los espectadores, a partir de ello, descubren el contenido de la historia, se generan o mantienen "bastantes puntos de contacto entre uno y los otros para que el recuerdo que nos recuerdan pueda construirse sobre una base común”. (Halbwachs, 2005, p.171). Obras, en donde se pueden reconocer elementos discursivos que están instalados socialmente y que permiten que sea de fácil reconocimiento de parte del público, ya que se fundan en los tópicos y las explicaciones públicas que se dieron de los acontecimientos en dictadura.

En el curso de la última década, el cine chileno desde el éxito del documental actores secundarios, (2004) permite reconocer identidades mantenidas en el olvido, hasta que algún evento, un proceso artístico o social las sitúan en un lugar articulador de memorias colectivas que, hasta ese momento, eran recuerdos íntimos. Del espacio privado se enuncia una historia con la capacidad de evocar una memoria colectiva con la capacidad de dialogar con memorias consolidadas a nivel nacional, memorias hegemónicas que, junto a otros factores, no permitían que otras voces y cuerpos pudieran articularse para enfrentar un nuevo relato sobre el periodo, narraciones presentadas en un contexto que les permite instalarse como una de las otras verdades que se construían de la resistencia a la dictadura.

En este proceso, una de las funciones de la memoria colectiva, "reside precisamente en la facultad que ofrece a los individuos y grupos para articular la ruptura -el acontecimiento contingente, a veces devastador y siempre vivido de un modo más o menos traumático- con la continuidad de los recorridos individuales y de las estructuras sociales. En otras palabras, la memoria es la condición indispensable de la permanencia de un sistema de comportamientos, valores o creencias en un mundo que cambia por definición” (Rousso, 1991, p.5).

Para que se expresen aquellas memorias, ¿qué cambio?; el contexto de producción y de exhibición de esa memoria, a través de los testimonios/personajes, y también de los realizadores que se decidieron a contar esa historia. Entonces se produce el doble vínculo del documental; por una parte se articula un relato que revela un episodio o un grupo y por otro, sistematiza una identidad olvidada, propone fijeza y estabilidad a la experiencia que se construye socialmente. Porque este tipo de cine, "opera y contribuye a la construcción de una identidad: permite determinar quiénes son los que conforman el nosotros que comparte esa mirada sobre el mundo y quiénes son esos otros de los que es necesario diferenciarse”. (Sartora, Rival, 2007, p.106). 
Siguiendo los postulados de Maurice Halbwachs, (1989) se podría apreciar que la fijación y reconstrucción del pasado es posible debido a la presencia de marcos sociales reconocidos por el proceso de memoria y características que configuran una identidad. El documental, como "el contenido del recuerdo siempre es tripartito hace referencia a algo ocurrido, a un sujeto que ha vivido y recuerda esa experiencia, y a otro u otros sujetos que forman parte de ella". (Ramos, 1989, p.69). El cine como vehículo de memoria pone al servicio de otras memorias, recuerdos que no estaban ni aislados ni eran individuales; sino que fueron vividos por todos quienes participaron del relato que se construye, es trasmisor de un marco de memoria que se evidencia.

Las obras eligieron a sujetos y acontecimientos que permiten a los personajes/testimonios mostrar algunas características de la memoria, por ejemplo, la condición social que se fija, y el cómo se recuerda. El formato elegido asume importancia y determina "el uso del lenguaje para describir lo que ocurre y sus pretensiones concomitantes de objetividad", (Ramos, 1989, p.70), este recurso permite dar un halo de pluralidad a las interpretaciones de los recuerdos y explicita que dicha fijación no es definitiva, ya que "mis recuerdos coexisten con los recuerdos de los demás y que esa coexistencia lleva a una tupida interpretación comunicativa de la que resulta un pasado reconstruido que es producto de todos y de ninguno en particular" (Ramos, 1989, p.71).

Las identidades y los grupos encuadran una memoria colectiva y estabilizan un recuerdo. Los principales marcos; el espacio y el tiempo; son vinculados a la experiencia del grupo representado, "la razón más decisiva a favor de la fusión entre recuerdo y marco radica en mostrar que, a falta de ella, los recuerdos se volatilizarían y la memoria no podría operar. Son los marcos los que le proporcionan estabilidad y persistencia”. (Ramos, 1989, p.73).

El espacio evoca, se refiere, contextualiza, gatilla un proceso que permite que los recuerdos, a través del tiempo, se vinculen con el grupo. Es, la disgregación de ese grupo social la que finaliza cuando aparece una película y es capaz de proponer una identidad y una interpretación del grupo y de sus relaciones como individuos "no hay recuerdos sin vida social, pero tampoco hay vida social sin recuerdo". (Ramos, 1989, p.76). Es este movimiento retro alimentador el que le otorga una impronta de futuro.

En la disputa de las memorias, se ponen en relieve las expresiones de resistencias; la pluralidad de las memorias colectivas y la existencia de la memoria individual con alojamiento en la realidad cimentada desde los regímenes democráticos, caracterizados, en un primer momento, por sus marcos rígidos y excluyentes, lo cual generó que, pocos años después la ciudadanía tomara aquella propuesta de memoria como una verdad que, por no representar la gama de visiones y acciones 
que configuraron el periodo recordado, carecía de legitimidad y consenso en los sectores antidictatoriales,: "El problema de toda memoria oficial es el de su credibilidad, de su aceptación y también el de su organización. Para que emerja en los discursos políticos un fondo común de referencias que pueden constituir una memoria nacional, es indispensable un intenso trabajo de organización para superar el simple montaje ideológico por definición precario y frágil”. (Pollak, 2006, p. 24).

En el cine, circulan memorias que también se tensionan a partir de la interacción entre lo individual y lo colectivo, lo cual obliga a significar y resignificar los recuerdos, estableciéndose un dialogo permanente entre las memorias propuestas. A nivel cinematográfico puede entenderse desde actores que interpretan memorias generadas por sucesos decididos por otros, pero que los involucraron a ellos. Usan como punto de análisis una misma temática tensionando el contexto político y social, y sus vinculaciones morales y afectivas, relatos que reducen el contexto en función de destacar voces centrada en las emociones y los afectos, expresados en primera persona, por realizadores/as, que son parte de un "trabajo de construcción de sentidos que no es mera re-construcción retórica ni ideológica de clisés de aquella generación, sino rescate, relectura y apropiación de parte de quienes se sitúan ahora en el lugar del heredero despojado, eligiendo intencionalmente los sentidos de algunas orientaciones estéticas e ideológicas para reactualizarlas en el contexto político en el que actúan en el presente" (Amado, 2009, p. 88), son una expresión de la vinculación de las experiencias construidas a través de su estrecha relación con otros sujetos, portadores de una memoria colectiva encuadrada en la militancia de aquellos años. Estas características podemos encontrarlas en Reinalda del carmen, mi mamá y yo, o El Edifico de los Chilenos, (Chile, 2008y 2010) o Los Rubios y M, (Argentina, 2003 y 2007).

Surge entonces la necesidad de precisar el espacio que ocupa el cine, en el marco de los procesos de memoria. El cine puede ser un vector o dispositivo de memoria y/o también puede instalarse como un lugar, en términos generales utiliza ambos espacios, aunque en una cinta de ficción predomine más la idea de vector, también tiene elementos que permiten entenderla como un lugar virtual de memoria, ya sea en su producción como en su circulación posterior y su instalación como un espacio promotor.

Las imágenes se presentan como una interpretación y fijación de un momento que se resiste dignamente al paso implacable y mortífero del tiempo. Las imágenes cinematográficas, que relatan los periodos dictatoriales son ejercicios que construyen la memoria reciente y se ubican como parte de las obras que le tironean a la sombra del olvido. La ficción y el documental son géneros que recuperan un tiempo pasado para confrontarlo con el presente y desde ese lugar, se dimensiona si cumplen una función de promotores de memoria, de "medio" de memoria, que 
construye una narración capaz de convocar y evocar una experiencia necesaria de ser vehiculizada. También se puede instalar como un lugar virtual de memoria, que exhibe un proceso de producción material que fijó ese pasado, y el uso que se le dio, convirtiéndola "en un documento de la "realidad", en una fuente de la historia. De esta manera fue perdiendo su carácter de representación para transformarse en materialidad del pasado, es decir, en huella” (Raggio, 2009, p.54), propone la autora sobre la cinta La Noche de los Lápices, (Argentina, 1986)

Estos lugares virtuales de memoria, situado en placas digitales o cintas analógicas, alojados en computadores que permiten instalar la película como parte de un proceso de memoria necesario para que no se olvide una fecha, un acontecimiento, un lugar, un tiempo. La película articula un relato que está presente en la memoria de las personas, se instala como parte de los "rituales de una sociedad sin ritual; sacralización pasajera en una sociedad que desacraliza, fidelidades particulares en una sociedad que pule los particularismo, diferenciaciones de hecho en una sociedad que nivela por principio: signos de reconocimiento y de pertenencia de grupo en una sociedad que tiende a reconocer sólo a los individuos iguales e idénticos" (Nora, 2000, p.5). Es un lugar de memoria virtual que no sólo evoca los hechos ocurridos, narrados, interpretados, sino que su producción contextualiza y simboliza el tiempo en que se estrenó. Es necesario dejar consignado que no toda película es un lugar virtual de memoria, el cine podría cumplir un rol que presenta, instala o vehiculiza una memoria, careciendo de valor en sí mismo el cómo se relata la historia, ya que el valor estaría dado por el acontecimiento o el sujeto que se recuerda. Ser un lugar de memoria virtual es un atributo que no puede extenderse a todas las películas, ya que muchas de ellas, no alcanzan a constituirse como parte del recuerdo de aquel acontecimiento, sino como un gatillador que lo representa.

El cine como dispositivo de memoria, tiene una pretensión de veracidad que no es cuestionable, ni siquiera cuando se opta por el género de ficción. Si una película se propone contar una historia usando imágenes del periodo o recreándolas y el público es capaz de reconocer aquella opción, es una cinta que pretende ser veraz, contar en lo medular una historia, sometiendo la ficción a la veracidad de los hechos, aunque, particularmente, sean producto de la imaginación. Son narraciones que no se ajustan a un hecho concreto, pero presentan sujetos y argumentos que representan el espacio y el tiempo pasado: la existencia de una dictadura; y la resistencia organizada a ella; la apropiación de niños; la configuración de una sociedad fracturada y dividida entre represores y víctimas; la vigencia de la tortura, del miedo, de la encarcelación y el exilio, son características de un periodo representado en la película, reconocido por los espectadores, que actúa como colaborador en el entendimiento del periodo histórico y sus claves sociales. 
El cine se instala en el proceso de memoria, en el marco de los medios de comunicación convertidos "en poderosos dinamizadores del recuerdo colectivo y en que las decisiones en este ámbito comienzan a ser origen y desencadenantes de complejos procesos sociales. La memoria social contemporánea es cada vez más una "memoria cultural", que se define por la popularización de la historia, específicamente por la historia contada a través del cine y la televisión”. (Baer, 2006, p. 115).

La reconstrucción del espacio es una invitación a rememorar el tiempo, en donde lo real y la representación se funden para dar paso a un relato verosímil, que desde un punto de vista pone en circulación una memoria sobre el periodo.

La condición de la cinematografía, no distinta a la de los sujetos, tiene olvidos, las historias se relatan encuadrándolas, reduciendo la amplitud de dimensiones y fijaciones que tiene la memoria. Esta limitante se debe a las características del formato, y a los condicionantes de quién articula el discurso: "toda narrativa del pasado implica una selección. La memoria es selectiva; la memoria total es imposible. Esto implica un primer tipo de olvido "necesario" para la sobrevivencia y el funcionamiento del sujeto individual y de los grupos y comunidades. Pero no hay un único tipo de olvido, sino una multiplicidad de situaciones en las cuales se manifiestan olvidos y silencios, con diversos "usos" y sentidos". (Jelin, 2002, p.20). Olvidos que no mantienen esa permanencia como condición irresoluta, permanente, estanca, pueden activarse a través de narraciones, de contextos que otorgan elementos que hacen posible que salgan de esa condición, ocurre lo mismo con las memorias, las cuales pueden pasar al olvido sino cuentan con emprendimientos que las hagan permanecer en el recuerdo.

Hacer una película es un ejercicio que desde el presente re-escribe el pasado, ya sea desde la ficción, donde el proceso de creación permite tener el control general del relato, o desde los testimonios, que pocas veces llegan a ser confesiones limitándose a crear una narración a través de la memoria de otros. Presenta la experiencia de el/los protagonistas en relación a acontecimientos, sujetos y objetos. Por ejemplo, los documentales arman una historia "que una o más personas, al reunir sus recuerdos, pueden describir con suma exactitud hechos u objetos que vimos al mismo tiempo que ellas, y reconstruir incluso toda la secuencia de nuestros actos y nuestras palabras en circunstancias definidas, sin que nosotros recordemos nada de eso" (Halbwachs, 2005, 165).

Se crea un relato que, desde su subjetividad, representa la trayectoria del/los personajes. "Aunque sea técnicamente difícil o imposible captar todos esos recuerdos en objetos de memoria confeccionados hoy, el cine es el mejor soporte para hacerlo: de allí su papel creciente en la formación y reorganización, y por lo tanto en el encuadramiento, de la memoria. El cine se dirige no sólo a las 
capacidades cognitivas, sino que capta las emociones”. transformándose en un importante lugar y/o vehículo de memoria. (Pollack, 2006, p.27).

El cine permite construir memorias que van generando y/o reforzando narraciones colectivas que permanecían dispersas, que eran invisibles o padecían de una quieta apatía por parte de sus protagonistas o de los productores de memoria. $\mathrm{Su}$ proceso cognitivo-emocional masifica una idea y genera otras en los espectadores, permitiendo que el "acontecimiento rememorado o "memorable" (sea) expresado en una forma narrativa, convirtiéndose en la manera en que el sujeto construye un sentido del pasado, una memoria que se expresa en un relato comunicable, con un mínimo de coherencia” (Jelin, 2002, p.27). Esta construcción se expresa en películas que reconstruyen un periodo anterior tratando de darle un sustento a su accionar, sin intentar dar cabida a todas las "verdades", ni presentándose como una "verdad" total, sino más bien es la interpretación de la trayectoria de vida de sus testimonios. El cine que existe sobre el tema tiene dos características contrapuestas; por una parte, tiene la pretensión de construir la "verdad" de todo un proceso, abusando de estereotipos que permiten que el espectador identifique y acepte la interpretación sin necesidad de cuestionar sus bases, ya que las asume como fiables. Y por otra, cuenta una historia reducida vinculada a quienes no subieron al podio de los "triunfadores" cuando los procesos transicionales comenzaron a materializarse.

La principal tensión generada en este estadio de disputa, que no sólo se expresa en el cine, también en la literatura, la poesía, la música; es que quienes se han sentido marginados de estas interpretaciones dominantes, no logran que su voz sea considerada en la construcción de una memoria país, instalada, principalmente, a través de las diferentes canales que tiene el Estado. Son relegados al silencio y a el olvido, ocultados por una memoria estática, reiterativa, olvidadiza, que no devela la complejidad del periodo y la multiplicidad de personajes que le dieron vida.

La cinematografía que ha logrado masificarse en Chile y Argentina, representa "los procesos y actores que intervienen en el trabajo de construcción y formalización de las memorias. ¿Quiénes son esos actores? ¿Con quienes se enfrentan o dialogan en ese proceso? Actores sociales diversos, con diferentes vinculaciones con la experiencia pasada - quienes la vivieron y quienes la heredaron, quienes la estudiaron y quienes la expresaron de diversas maneras- pugnan por afirmar la legitimidad de su "verdad". Se trata de actores que luchan por el poder, que legitiman su posición en vínculos privilegiados con el pasado, afirmando su continuidad o su ruptura. En estos intentos, sin duda los agentes estatales tienen un papel y un peso central para establecer y elaborar la "historia/memoria oficial". Se torna necesario centrar la mirada sobre conflictos y disputas en la interpretación y sentido del pasado, y en el proceso por el cual algunos relatos logran desplazar a 
otros y convertirse en hegemónicos" (Jelin, 2002, p.40). Esta memoria es construida legítimamente por sujetos que tuvieron preponderancia y virtud en aquel periodo; actores que lograron imponer o negociar los términos del proyecto democratizador, sin embargo, a ese ejercicio de reconstrucción puede objetársele el usurpar y totalizar los recuerdos de un tiempo histórico que involucra a grupos más amplios. Optan por dar estabilidad a la memoria impuesta a partir de la negación de otras memorias, y parte de la materialización de esa voluntad, es la utilización de imágenes cinematográficas que perpetúan una memoria como un acontecimiento estático, que no da cuenta de los cambios que se producen en toda sociedad.

Cuando una obra tiene una base político/social, los silencios, olvidos y tensiones narrativas e históricas que tiene el formato cinematográfico, podrían transformarse en una limitante que impone el medio, que podría agudizarse por la condición subjetiva del autor, quien podría asumir un punto de vista "único" y "totalitario" de la historia presentada, haciéndola coincidir con las interpretaciones históricas que predominan en el quehacer político y social. Transformándose en registros centrales que afectan negativamente las memorias individuales y colectivas, sin embargo, son riesgos que pueden reducirse si se busca la creación de una historia que represente una memoria amplia y no excluyente, lo cual no significa la incorporación de todos los relatos, sino la amplitud del que se presenta.

La existencia de una cinematografía plural, amplia, innovadora, inclusiva y crítica, entrega herramientas para que en el proceso de memoria colectiva e individual existan referentes que permitan a través de imágenes del pasado y el presente, generar propuestas integradoras.

\section{Referencias bibliográficas}

Amado, Ana, (2009) La Imagen Justa: cine argentino y política (1980 - 2007). Buenos Aires, Edit: A oscuras Colihue Imagen.

Baer, Alejandro. (2006) Holocausto. Recuerdo y representación. Capítulo IV: "El cine y la televisión: el horror en la pantalla”. Madrid, Losada

Bratkievich, A. (2010), Representaciones directas e indirectas del abuso militar en el cine argentino de los ochenta. En El Tiempo Presente como Campo Historiográfico, Uruguay, Ediciones Cruz del Sur.

Jelin, Elizabeth, (2002) Los trabajos de la memoria. Madrid y Buenos Aires, Siglo XXI.

Halbwachs, M. (2005) Memoria individual y memoria colectiva. En Estudios Nº 16, Centro de Estudios Avanzados de la Universidad de Cordoba, Argentina, Universidad de Córdoba. 
Huyssen, Andreas. (2002) Pretéritos presentes: medios, política y amnesia, en busca del futuro perdido. Cultura y memoria en tiempos de globalización, México, Fondo de Cultura Económica.

Nora, Pierre, (2009) Les Lieux de Mémoire, Santiago, Lom.

Novaro, M, Palermo, V, (2003) Historia Argentina, La Dictadura Militar 1976/1983, Del Golpe de Estado a la Restauración Democrática. Buenos Aires, Paidos.

Moyano, Cristina, (2010) La memoria militante y el uso testimonial en la historia política y el tiempo presente en Chile: de lo estructural y lo subjetivo. En "Memorias de militantes políticos en Chile e Historia del Presente" (Pp. 191-212) en Bresciano, Juan (edit) "El Tiempo Presente como campo historiográfico. Ensayos teóricos y estudios de casos" Ed. Cruz del Sur, Uruguay, 2010.

Oberti, P, Pittaluga, R, (2006) Memorias en montaje, Escrituras de la militancia y pensamiento sobre la historia. Buenos Aires, Ediciones el Cielo por asalto.

Pollak, M. (2006), Memoria, Olvido, Silencio. La producción social de identidades frente a situaciones límites. En Memoria Olvido y Silencio, La Plata, Al Margen Editora.

Raggio, Sandra, (2009) "La Noche de los Lápices: Del testimonio judicial al relato cinematográfico", en Feld, C. et Stites Mor, J., El pasado que miramos. Memoria e imagen ante la historia reciente, Buenos Aires, Paidós.

Richard, Nelly (2010) “Critica de la Memoria (1990 - 2010), Santiago, Edit, Universidad Diego Portales.

Rousso, Henry, (1991) Pour une histoire de la mémoire collective: l'après Vichy”, en Peschansky, Pollak y Rousso (eds.), Histoire politique et sciences sociales. Paris, Complexe.

Ramos, Ramón, (1989) “Maurice Halbwachs y la memoria colectiva”, España, en Revista de occidente, $n^{\circ} 100$.

Sartora J, Rival S, (2007) Imágenes de lo real, Argentina, Libraria.

Vezzetti, Hugo, (2009). Sobre la Violencia Revolucionaria, memorias y olvidos. Argentina, Siglo XXI. 